\title{
Multimodal imaging in bilateral ocular ischaemic syndrome with anterior ischaemic optic neuropathy in a case of Takayasu arteritis
}

\author{
Subhakar Reddy 주, Mudit Tyagi, Anjali Suresh, Avantika Dogra
}

Smt Kanuri Santhamma Center for Vitreo-Retinal Diseases, LV Prasad Eye Institute, Hyderabad, India

\section{Correspondence to Dr Mudit Tyagi; drmudittyagi@gmail.com}

Accepted 30 May 2020

\section{DESCRIPTION}

A 27-year-old woman, known case of Takayasu Arteritis on systemic immunosuppression, was referred by her rheumatologist for ocular evaluation as the patient had problems of floaters and diminution of vision in both eyes since 1 month. She had bilateral occlusion $(>80 \%)$ of her carotid arteries and had been started on low molecular weight heparin by her treating physician. On examination, her best corrected visual acuity (BCVA) was 20/100 N6 in the right eye and 20/125, N6 in left eye. The anterior segment examination of both eyes was essentially normal. Intraocular pressure in right and left eyes was $12 \mathrm{~mm} \mathrm{Hg}$ and $13 \mathrm{~mm}$ $\mathrm{Hg}$, respectively. Pupils in both eyes were sluggishly reacting to light. Fundus examination of both eyes (figure 1A,B) showed the presence of neovascularisation of optic nerve head (NVD) and optical coherence tomography (OCT) of macula was essentially normal (figure $1 \mathrm{~A}, \mathrm{~B}$ inset)

An ultrawide field fundus fluorescein angiography (UW-FFA) of both eyes revealed delayed arm to retina time of $56 \mathrm{~s}$ along with the presence of numerous microaneurysms, NVD, few

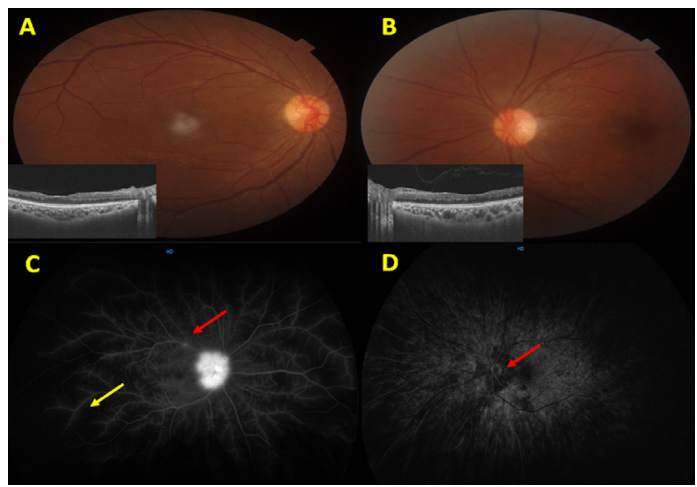

Figure $1 \quad(A, B)$ Fundus photograph of right and left eyes, respectively, showing neovascularisation of optic nerve head (NVD) with inset showing normal optical coherence tomography at macula. (C) Late arteriovenous phase ultrawide field fundus fluorescein angiography (UW-FFA) of right eye showing NVD and an area of vascular staining with perivascular sheathing (red arrow), multiple microaneurysms, perivascular leakage and extensive peripheral capillary non-perfusion areas (yellow arrow). (D) An arterial phase UW-FFA of left eye showed delayed peripapillary choroidal filling and optic disc hypoperfusion (red arrow). Small white opacity temporal to fovea in (A) and just adjacent to disc in (B) was an artefact.

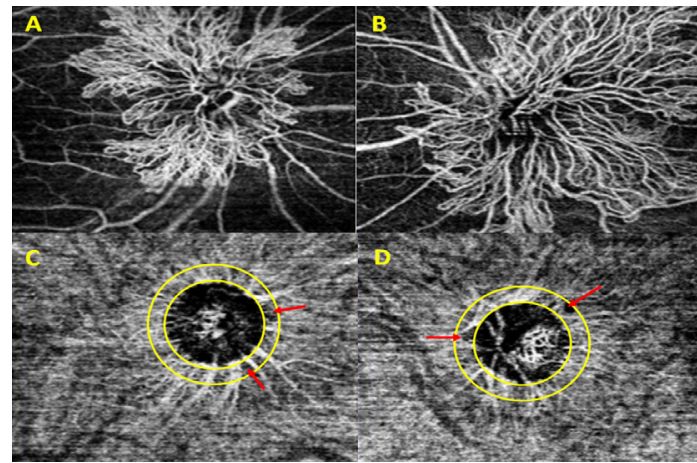

Figure 2 (A, B) Optical coherence tomography angiography (OCTA) at optic nerve head of right and left eyes, respectively, showing extensive florid neovascularisation of optic nerve head. (C, D) OCTA at choriocapillaries slab of right and left eyes, respectively, showing segmental peripapillary flow deficit areas (red arrow).

areas of perivascular staining with minimal leakage, peripheral capillary non-perfusion areas (figure 1C) and delayed peripapillary choroidal filling (figure 1D) with optic disc hypoperfusion.

OCT angiography (OCTA) of the optic disc confirmed the presence of NVD in the optic nerve head slab of both eyes (figure 2A,B) along with peripapillary segmental flow void areas in choriocapillaries slab of both eyes using Image $\mathrm{J}$ software (figure 2C,D) which helped in diagnosing an anterior ischaemic optic neuropathy. Hence,

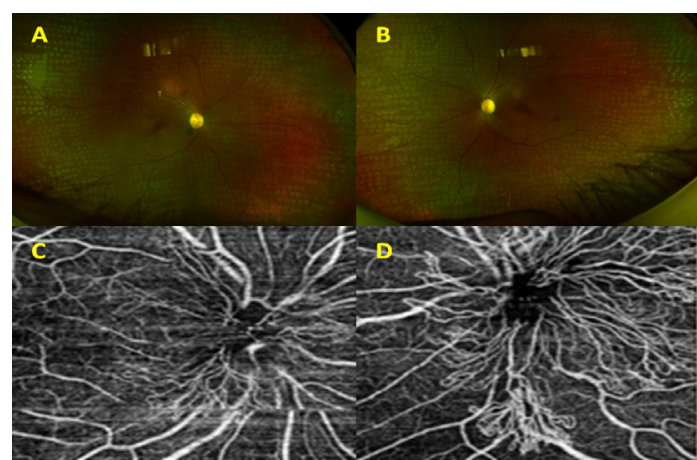

Figure $3(A, B)$ Fundus photograph of right and left eyes, respectively, showing pan retinal photocoagulation laser marks. (C, D) Optical coherence tomography angiography of optic nerve head demonstrating regressing neovascularisation of optic nerve head of right and left eyes, respectively. 
a final diagnosis of bilateral stage 4 Takayasu retinopathy with anterior ischaemic optic neuropathy and ocular ischaemic syndrome was made. ${ }^{1-3}$ Panretinal photocoagulation was done in both eyes and subsequently she underwent bilateral carotid endarterectomy for carotid artery occlusion. At 2-month follow-up, IOP in both eyes was $14 \mathrm{~mm} \mathrm{Hg}$ and her BCVA had improved to 20/40 and 20/60 in right and left eyes, respectively. Fundus examination showed pallor of optic nerve head secondary to ischaemic optic neuropathy along with regressing NVD (figure $3 \mathrm{~A}, \mathrm{~B}$ ) which was confirmed on OCTA (figure 3C,D).

Takayasu arteritis is a chronic granulomatous inflammatory arteritis involving mainly the large arteries of the body. ${ }^{4}$ Ocular manifestations are due to affection of the carotid arteries leading to improper perfusion of the ophthalmic artery. Ocular manifestations have been described by various groups ranging from involvement of retinal veins and occlusion of large arteries, microaneurysms, ischaemic optic neuropathies ${ }^{56}$ to complications like cataract, neovascularisation of the iris

\section{Patient's perspective}

I'm under regular follow-ups with my rheumatologist for Takayasu arteritis and I'm thankful to my rheumatologist for timely referral to ophthalmologist for this eye disease. Knowing the fact that I may have subnormal vision for rest of my life but I'm happy that further complications were prevented.

\section{Learning points}

- Optical coherence tomography angiography (OCTA) can help in assessing peripapillary flow void areas and can help unveil an underlying anterior ischaemic optic neuropathy.

- Multimodal imaging especially OCTA combined with fundus fluorescein angiography can be an useful tool in diagnosing anterior ischaemic optic neuropathy and ocular ischaemic syndrome in cases of Takayasu arteritis. and retina leading to vitreous haemorrhage and neovascular glaucoma.

Our case showed the presence of peripapillary flow deficit areas in OCTA which were evaluated using Image $\mathrm{J}$ software ${ }^{8}$ along with delayed peripapillary choroidal filling and optic disc hypoperfusion on UW-FFA ${ }^{9}$ which helped us in arriving at a diagnosis of an underlying ischaemic optic neuropathy.

To conclude Takayasu arteritis has a gamut of varied ocular manifestations with unexplained vision loss in some cases and multimodal imaging can help in arriving at correct diagnosis and treatment in such cases.

Contributors SR: writing manuscript, editing and review. MT: manuscript editing and review. AS: photography. AD: manuscript review.

Funding The authors have not declared a specific grant for this research from any funding agency in the public, commercial or not-for-profit sectors.

Competing interests None declared.

Patient consent for publication Obtained.

Provenance and peer review Not commissioned; externally peer reviewed.

ORCID iD

Subhakar Reddy http://orcid.org/0000-0001-5683-7334

\section{REFERENCES}

1 Uyama M, Asayama K. Retinal Vascular Changes in Takayasu's Disease (Pulseless Disease), Occurrence and Evolution of the Lesion. In: De Laey JJ, ed. International Symposium on fluorescein angiography Ghent 28 March-1 April 1976. 9. Dordrecht: Documenta Ophthalmologica Proceedings Series, Springer, 1976.

2 Chotard G, Diwo E, Coscas F, et al. Fluorescein and OCT angiography features of Takayasu disease. Ocul Immunol Inflamm 2019:27:774-80.

3 Chun YS, Park SJ, Park IK, et al. The clinical and ocular manifestations of Takayasu arteritis. Retina 2001:21:132-40.

4 Arend WP, Michel BA, Bloch DA, et al. The American College of rheumatology 1990 criteria for the classification of Takayasu arteritis. Arthritis Rheum 1990;33:1129-34.

5 Leonard TJ, Sanders MD. Ischaemic optic neuropathy in pulseless disease. Br J Ophthalmol 1983;67:389-92.

6 Tian G, Chen Q, Wang W. Takayasu arteritis presenting as isolated anterior ischemic optic neuropathy. Int Ophthalmol 2018;38:823-8.

7 Peter J, David S, Danda D, et al. Ocular manifestations of Takayasu arteritis: a crosssectional study. Retina 2011;31:1170-8.

8 Gandhi U, Chhablani J, Badakere A, et al. Optical coherence tomography angiography in acute unilateral nonarteritic anterior ischemic optic neuropathy: a comparison with the fellow eye and with eyes with papilledema. Indian J Ophthalmol 2018;66:1144-8.

9 Arnold AC, Hepler RS. Fluorescein angiography in acute nonarteritic anterior ischemic optic neuropathy. Am J Ophthalmol 1994;117:222-30.

Copyright 2020 BMJ Publishing Group. All rights reserved. For permission to reuse any of this content visit

https://www.bmj.com/company/products-services/rights-and-licensing/permissions/

BMJ Case Report Fellows may re-use this article for personal use and teaching without any further permission.

Become a Fellow of BMJ Case Reports today and you can:

- Submit as many cases as you like

- Enjoy fast sympathetic peer review and rapid publication of accepted articles

- Access all the published articles

- Re-use any of the published material for personal use and teaching without further permission

Customer Service

If you have any further queries about your subscription, please contact our customer services team on +44 (0) 2071111105 or via email at support@bmj.com.

Visit casereports.bmj.com for more articles like this and to become a Fellow 